\title{
The state of the art in stem cell biology and regenerative medicine: the end of the beginning
}

\author{
Evan Y. Snyder ${ }^{1}$
}

With translational stem cell biology and Regenerative Medicine (the field to which the former gave rise) now over a quarter century old, it is time to take stock of where we have been and where we are going. This editorial overview, which serves as an introduction to this special issue of Pediatric Research dedicated to these fields, reinforces the notion that stem cells are ultimately intrinsic parts of developmental biology, for which Pediatrics represents the clinical face. Although stem cells provide the cellular basis for a great deal of only recently recognized plasticity programmed into the developing and postdevelopmental organism, and although there is enormous promise in harnessing this plasticity for therapeutic advantage, their successful use rests on a deep understanding of their developmental imperatives and the developmental programs in which they engage. The potential uses of stems are ranked and discussed in the order of most readily achievable to those requiring extensively more work. Although that order may not be what was contemplated at the field's birth, we nevertheless retain an optimism for the ultimate positive impact of exploiting this fundamental biology for the well-being of children.

l: is most appropriate that a special issue dedicated to taking stock of the accomplishments and future challenges of the stem cell field should be undertaken by a journal devoted to research on pediatric disorders. The solid-organ stem cell field - which arguably launched and enabled the discipline of Regenerative Medicine-achieved its first preclinical therapeutic success in a model of a pediatric disease (1), offering proof of concept that this tool might someday join medicine's armamentarium. Admittedly the hematopoietic stem cell field, pioneered by TIill and McCulloch (2), had been tackling pediatric disorders for three decades prior to that, but blood was known to be a renewable system in contrast to brain, heart, muscle, pancreas, and lung. It was the recognition that these latter organs-heretofore regarded as rigidly predetermined in form, function, and cellular content and unforgiving of insult-nevertheless harbored cells far beyond embryogenesis with unanticipated degrees of plasticity, multipotency, and self-renewable capacity that the notion of a Medicine based on natural or induced regenerative capacity was born. These cells-capable of being isolated, expanded, passaged, cryopreserved, and transplanted-represented the cellular basis for a great deal of previously unrecognized plasticity programmed into developing and postdevelopmental organs. Therapeutic advantage might be realized, it was reasoned, by harnessing this plasticity.

But there is an even more compelling reason why the stem cell field owes an intellectual debt to Pediatrics: although in the rush to generate treatments it tends to be forgotten, stem cells, first and foremost, are integral components of developmental biology_for which Pediatrics is the clinical face. Hence it further makes sense that the promise of translational stem cell biology should find its greatest promise in developing systems.

As a witness to and participant in the birth, infancy, and maturation of the stem cell field, I would like to use this Introductory Overview to offer a more personal and somewhat philosophical "10,000-foot high" perspective of where I think we have been and where I think we are going. The field is no longer new. And we have divested ourselves of the field's early naivety of thinking that the road to cures and treatments would be easy ("the cells know what to do" (3-8)) without having to engage in the "intellectual heavy-lifting" of identifying the intricacies of the molecular pathways underlying development and pathology. As a neuroscientist, I will focus principally on the role of stem cells in the nervous system. Indeed, neural stem cells (NSCs) were arguably the first bonafide solid organ stem cell isolated $(3,9)$. However, we have learned that, in broad strokes, many, if not most, of the guiding principles that apply to one organ system are applicable to others as well (with, of course, organ-specific fine-tuning).

As indicated above, we now accept that stem cells are components of intrinsic developmental programs. Teleologically their task is first to engage in organogenesis and then to maintain the homeostasis of that organ throughout life in the face of perturbations, including normal aging. They can achieve this latter goal through a number of mechanisms, cell replacement being but one. Most of these strategies require a

\footnotetext{
${ }^{1}$ Center for Stem Cells \& Regenerative Medicine, Sanford Burnham Prebys Medical Discovery Institute and Department of Pediatrics, University of California-San Diego, La Jolla, California. Correspondence: Evan Y. Snyder (esnyder@sbp.edu)

Received 26 September 2017; accepted 2 October 2017; advance online publication 13 December 2017. doi:10.1038/pr.2017.258
} 


\section{Review | snyder}

great deal of complex cross-talk between transplanted stem cells and the host niche (which is comprised of a diversity of cell types, components, and molecules, including extracellular matrix, stroma, vascular endothelial cells, resident and invading macrophages, and metabolic waste and by-products, as well as endogenous stem cells in various stages of selfrenewal, differentiation, and maturation (ranging from "quiescent label-retaining cells" to "transit amplifying cells" to immature cell type-specific precursors). It is these "organogenic" and homeostatic programs that the translationally-oriented stem cell biologists hopes to invoke or reinvoke. And to do that, they must first be understood. Figure 1 schematizes the cross-talk that undergirds a dynamic that ensues upon stem cell transplantation; both graft and host change in complex ways. It has taken a quarter of a century to begin to understand those arrows (the "language" of the stem cell) and it remains our challenge to appreciate (and respect) the inherent biological imperatives of the stem cell. It has become clear: any therapeutic intervention that works at cross-purposes to those imperatives is destined to fail.

Although political, ethical, and administrative considerations over the past two decades often forced the field to silo itself (e.g., "embryonic" vs. "fetal" vs. "adult"), stem cell biology is actually a "continuum" starting from extremely "plastic" cells derived from the "inner cell mass" of the blastocyst or from the "epiblast" with the potential to become any cell type ("pluripotent") to cells that "know" their "address" is in a particular organ ("tissue-specific" or "somatic") but are still quite malleable because they must yet put that multi-cell organ together. Whether a stem cell researcher obtains cells from the earliest end of that developmental spectrum (from the embryo) or from the oldest (the adult), that investigator must actually focus on what those cells would actually be doing during embryonic and fetal development. Scientists working with pluripotent stem cells (PSCs) are attempting to "instruct" their cells to be like those in the developing fetus; those working with adult cells are attempting to "fool" their cells into behaving as they did in fetal life. The essence of regenerative medicine, after all, is to "re-seed the lawn" or "reboot the computer". Indeed, injury and active degeneration appear to promote a recrudescence (at least transiently) in the adult of early developmental cues to which the stem cells can respond as if in an embryonic or fetal milieu (4-8). "Fate does not reflect potential, nor does potential portend fate" became our aphorism for years. This notion became even more apt with one of the most surprising revelations of the past decade: the continuum not only progressed from "pluripotence" to "somatic cell commitment" but can also be nudged backward as well. Through the forced "reactivation" of quiescent "stemness" genes (by exogenous nucleotides, microRNAs, drugs, small molecules, chromatin modifiers, proteins) ostensibly end-differentiated somatic cells can be pushed back in developmental time to behave like pluripotent cells. A key to a somatic cell's reacquisition of pluripotency is

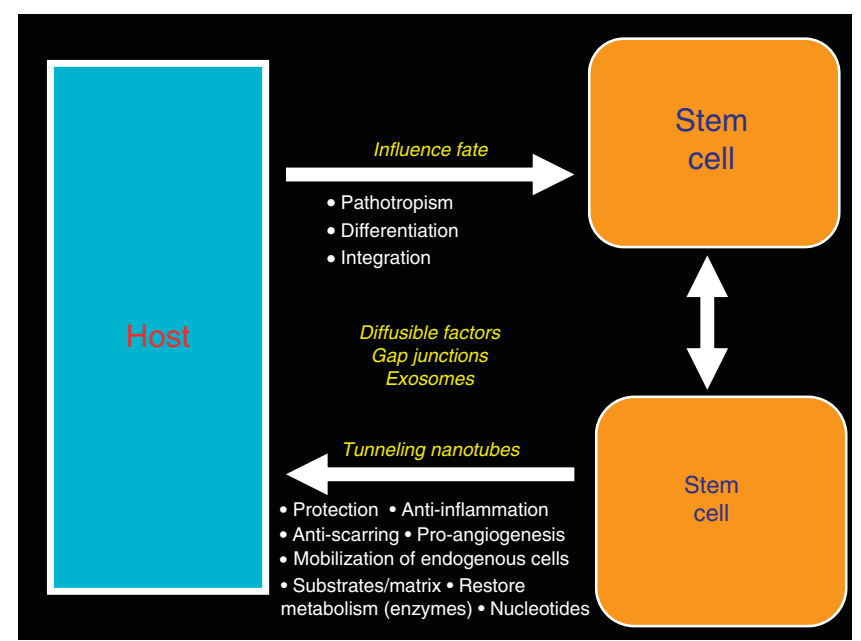

Figure 1. Cross-talk between the the transplanted stem cell and a host with pathology, as well as between stem cells themselves as they allocate a "division of labor".

re-opening its chromatin and increasing its histone acetylation while decreasing its histone methylation. When artificial means are used to promote such "reprogramming", the resultant cells are called "induced PSCs" (iPSCs). A fairly routine cocktail of genes has been identified for that purpose, typically involving various combinations of OCT4, SOX2, MYC, KLF4, NANOG, and LIN28. It should be noted that this strategy for de-differentiation, as first described by Yamanaka and colleagues $(10,11)$, may be different from the process of de-differentiation that the cytoplasm of an oocyte constitutively performs upon a somatic cell's nucleus that has been transferred into its environment, as first described by Gurdon (12), and is the basis of "somatic cell nuclear transfer (SCNT)". Those latter factors and mechanisms remain to be identified, suggesting that new surprises may be in store for the field.

It used to be thought that an iPSC retained the "epigenetic memory" of its "starting cell" prior to reprogramming (i.e., iPSCs derived from dermal fibroblasts were thought to be different from iPSCs derived from peripheral blood mononuclear cells). However, it became recognized that, after extensive passaging (e.g., $>16$ passages), these epigenetic marks were lost and all iPSCs basically behave similarly (13). It still remains a debate whether iPSCs and embryonic stem cells (ESCs) do, in fact, behave identically. Although developmental biologists engage in attempts to find the most primitive and naive "ground state" human ESC (hESC) (14) i.e., emulating the earlier inner cell mass as opposed to the later epiblast-for translational purposes, the consensus has emerged that the two pluripotent cell types are sufficiently similar in their attributes as to be regarded as equal in terms of efficacy as well as vigilance for safety (15). Much effort is being devoted of late to increasing the efficiency of reprogramming (which is still quite low at $<1 \%$ and stochastic) by attempting to emulate the more naive 


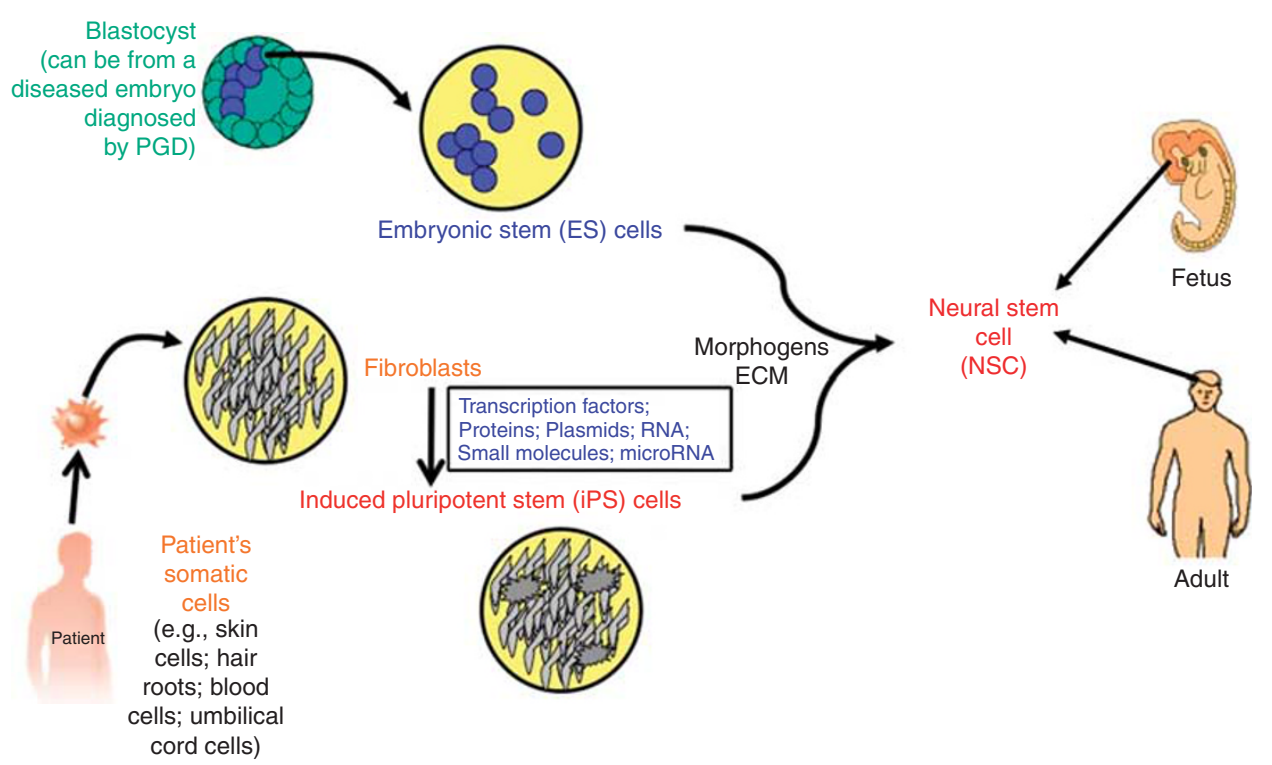

Figure 2. Although there are now many ways to obtain a neural stem cell (NSC), ultimately one must understand the developmental imperatives of that NSC and the developmental programs it will play out. ECM, extracellular matrix; PGD, preimplantation genetic diagnosis.

pluripotent state or by erasing even more epigenetic marks (e.g., via TET factors and/or using softer substrates).

Another surprise for classical developmental biologists was the fact that one somatic cell type can be "transdifferentiated" into a somatic cell of another lineage (in vitro and perhaps even in vivo) without going through an intermediate pluripotent stage. This transdifferentiation does not happen spontaneously. Fifteen years ago, a spate of papers erroneously reported spontaneous transdifferentiation which turned out to be an artifact from the previously unrecognized fusion of two different somatic cell types (16-18). But such an apparent change in identify does happen with the forced expression of lineage-determining genes. Hence, we now also speak of induced neurons ("iNs") (19), induced oligodendrocyte precursor cells (iOPCs) (20), induced cardiomyocytes (21) ("iCMs"), induced blood cells (22), etc.

It bears mentioning (as suggested in Figure 2) that regardless of how one chooses to generate somatic stem cells-whether isolated directly from the fetus, expanded from the adult, differentiated from ESCs, or generated from iPSCs - understanding and respecting the biological imperatives and "language" of that somatic stem cell (in our case, the NSC) remain the same. It is the NSC, for example, that will ultimately interface with a damaged host, spooling out its inherent molecular programs.

Although this Overview-and this special issue-will discuss the translational advances made by the stem cell field in Pediatrics, I would submit that the most profound contribution stem cell biology has made to Medicine in general is one of philosophy. Recognition of the existence of such malleable cells throughout life forced us to regard development and disease in less rigid and deterministic terms, and rather to adopt a model with more "plasticity", "responsiveness", and "flexibility". This new type of thinking

\author{
The role of the stem cell for neurological \\ disease/disability - now and in the future \\ -Prediction \\ -Prevention/intervention \\ -Protection \\ -Restoration \\ -Replacement
}

Figure 3. A subjective listing of the translational role of the stem cell for neurological disease and disability listed from top to bottom in a descending order of "closest to being realized" in terms of direct impact on children. Note that modeling disease ("prediction") is much more near-term than is direct "neural cell replacement".

certainly gave rise to the idea that Medicine might not only stop a disease process but also renew damaged terrain (i.e., the essence of Regenerative Medicine). It also gave rise to the idea that enriched environments and targeted rehabilitation through activity-dependent cues might reinvoke developmental programs and promote compensation for lost function even in the sick and elderly, and that perhaps no injury is truly the "end state".

For this editorial, I will describe how I see the future of the stem cell field unfolding translationally for Pediatrics (and Medicine in general). In Figure 3, I have listed, from top to bottom, the order in which I see this biology making a nearterm impact on the health care of the greatest number of patients. Note that I list "cell replacement" at the bottom. Although this action was, in fact, the aspiration that propelled Regenerative Medicine from its inception, it has proven to be the most frustratingly elusive. I am confident that we will get 


\section{Review | snyder}

there; but, in the course of pursuing that goal, we have come to learn about and, indeed, embrace the others higher on the list as perhaps being even closer to fruition and readily feasible. We also have (or must) come to the sobering realization that not all diseases are amenable to cell-based therapies. Yet even where pharmacological, genetic, surgical, and engineering solutions are better suited, stem cell biology can have a role in advancing them. In the following sections, I briefly deal with each potential use.

\section{PREDICTION-STEM CELLS FOR "DISEASE-IN-A-DISH" MODELING AND PERSONALIZED/PRECISION MEDICINE}

I believe that stem cells may actually have their most nearterm impact on health care by enabling us to model a given disease process in vitro-discern its underlying pathogenic and pathophysiological molecular mechanisms, map the defective pathways, derive diagnostic and prognostic biomarkers, identify novel drug targets, and then use the same stem cells in assays for the discovery of new or repurposed drugs against those targets. In this therapeutic scenario, it is not the cells that go into the patient but rather the drugs discovered from the cells that are administered.

This therapeutic approach begins with being able to model a disease with sufficient authenticity that one can "predict" the risk, onset, development, outcome, and drug response of a given disorder for a given patient.

The notion of attempting to model development and disease "in a dish" has actually been on the mind of investigators from the earliest days of the field. For the nervous system, for example, researchers wondered whether NSCs abstracted from patients with a given neurological disease would behave "in a dish" as they do in the patient's brain (23). However, prior to 2007 (11), isolating stem cells from an organ as inaccessible as the brain had to await the death of the patient and the donation of fresh postmortem tissue. Another approach was to generate hESCs from blastocysts that were not implanted following in vitro fertilization because preimplantation genetic diagnosis (PGD) had identified them as bearing a non-survivable monogenic disorder. These approaches, which rested on chance availability, were extremely limiting. With the development of "somatic cell reprogramming" (11), enabling the ready creation of human iPSCs (hiPSCs) from any accessible somatic cell (e.g., skin fibroblasts, peripheral blood mononuclear cells, hair follicles), investigators could generate and study cell types (e.g., cortical neurons) that were hitherto impossible to obtain from a living patient.

Given the ease and relatively non-invasive manner of obtaining starting cells for the creation of hiPSCs, one could profile such cells not only from a given patient but also that patient's first-degree relatives. Also similar cells could be obtained from large cohorts of patients with the same disease as well as unaffected siblings. Because the reprogrammed cells were pluripotent, one could also study the phenotypic expression in multiple lineages of a given genotype. For example, we might be able to start asking why, if a genetic defect such as that seen in Huntington's disease is present in all cells, is Huntington's disease primarily a neurodegenerative condition and not a cardiac disorder, - or is there a cardiac phenotype that is clinically masked? Finally, the advent of genomic editing techniques (e.g., CRISPR/Cas9) has made it possible to study the precise actions of a putatively pathogenic gene with great rigor: if a phenotype is directly related to a given gene defect, then it should disappear when the genetic defect is corrected in "diseased" hiPSC-derived neurons, and appear in neurons derived from normal hiPSCs into which the defect has been introduced. Such genetically-related hiPSC lines that differ only in the expression of the gene(s) in question are called "isogenic controls". Their use now makes for the most rigorous molecular studies in that gain and loss of function experiments can be readily perfomred.

Studying a disease "in a dish" can be pursued in one of two complementary ways. The derivatives of "normal" hiPSCs can be perturbed in ways believed to emulate a disease processe.g., oxidative or excitotoxic stress. Alternatively, derivatives of "diseased" hiPSCs (i.e., hiPSCs generated from somatic cells obtained from patients with particular diseases) can be profiled. The goal is (a) to identify underlying pathological mechanisms of a particular disease process (often by screening, in an unbiased non-hypothesis-drive fashion, libraries of microRNAs or small-interfering RNAs that identify a key gene through appearance of a disease-relevant phenotype following suppression of its function), and (b) to determine molecular "signatures" in the cells that might suggest diagnostic and prognostic biomarkers and drug targets. These signatures can be converted to assays that allow these same cells to be used in screens of libraries of thousands of small molecules and compounds in an unbiased high-throughput manner to identify drugs (or "leads" to drugs) that might serve protective, restorative, or compensatory functions based on their alteration of some disease process. The advantage of using stem cells as opposed to simply putting a reporter construct in a standard non-descript HELA or CHO cell line is that one can also do phenotypic screens-i.e., screen for certain behaviors of hiPSC derivatives that are relevant to reversing a disease process, e.g., neurite length, degree of migration, number of neurons vs. glia, etc. The type of libraries that be screened can be variable. Hits from a library of Food and Drug Administration-approved drugs could allow that drug to be repurposed and accelerated to clinical trials because it has already gone through the regulatory gauntlet.

Given that hiPSCs are patient specific, this use of stem cells inevitably dovetails with health care's growing interest in the power of personalized or precision medicine. As a stem cell biologist, I envision that someday every individual will have a bank of their own cells from which a molecular and functional database has been constructed and which can be interrogated throughout life (in conjunction with their electronic medical record), looking for biomarkers that might trigger the early intervention into an imminent disease process and/or guide 
the selection of pharmacogenetic-specific therapies (minimizing trial and error) and/or provide the starting population for cell-based therapeutics. Indeed, it is in the realm of personalized medicine that the true "predictive" potential of stem cells may come into play.

If personalized medicine is Medicine's future, then Pediatrics has the opportunity to have a unique role in spearheading the systematic launch of that epoch. Most attempts to identify informative biomarkers in patients have been hampered by selection bias-profiling a limited pool of individuals, typically in adulthood, who already have a given disease, requiring investigators to attempt reconstruction of a lifetime of epigenetic influences to make sense of an avalanche of 'omics data. Those data will inevitably be cherry-picked, biased, and retrospective. In contrast, pediatricians have the unique opportunity to start their observations of an individual patient at the beginning of life (not pre-selected) and follow that patient going forward. We have the ability (given reduced costs and improved technology) to generate hiPSCs from the discarded umbilical cord stumps of (theoretically) every newborn in a given hospital from which molecular and phenotypic data can be acquired and archived (24) (one obtains as routinely as one obtains footprints and blood spots) in an unbiased manner, with wide capture; thanks to the pediatrician's central role in health care for the first 1-2 decades of life, these data can be continually correlated prospectively with that individual's clinical course through infancy, childhood, and into adulthood. Which patients go on to develop autism, diabetes, learning disabilities, heart disease, inflammatory processes, cancer? Somewhat like a "molecular Framingham Project", this overall approach might serve to address a major challenge to the field of biomarker discovery and precision medicine-compensating for the wide range of "normal variation" of molecules that have no pathological clinical impact and, because hiPSCs can be rigorously

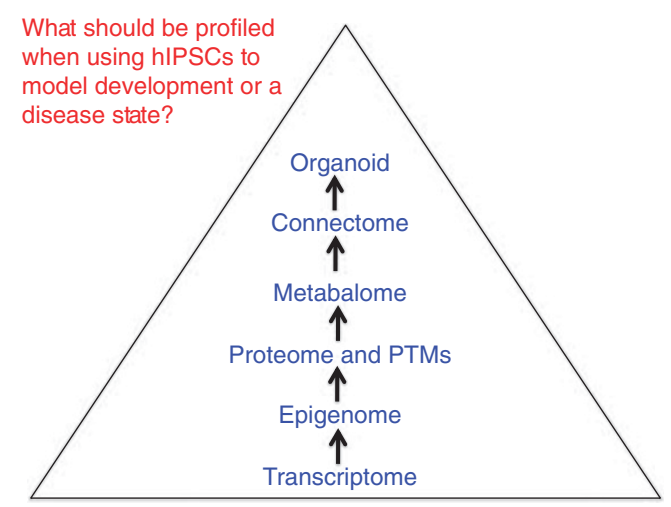

Figure 4. The "profiling pyramid". When using stem cells to model "diseases-in-a-dish", what should be profiled? The pyramid has genomics at its base but gradually ascends to a higher and higher organismal level of function where cells interact with each other and where there is an integration of multiple epigenetic inputs. An accurate reflection of development and disease using stem cells as model systems may depend on ascending the pyramid. hIPSC, human induced pluripotent stem cell; PTM, posttranslational modification. controlled and manipulated, moving beyond mere correlation to cause-and-effect through gain- and loss-of-function studies performed on differentiated cell types relevant to the disease in question (neurons, glia, cardiomyocytes, pancreatic betacells, skeletal or smooth muscle, etc.).

Although hiPSC technology has made large-scale prospective molecular and phenotypic profiling feasible in a patientspecific manner, critical stem cell-related issues admittedly remain to be answered for this approach to be both practical and fruitful.

\section{WHAT IS (ARE) THE RIGHT CELL TYPE(S) TO PROFILE?}

Although stem cell biologists have traditionally thought they wanted to study pure populations of a given cell type in culture (actually quite hard to achieve), in the actual vertebrate body, cells types from a single lineage (even from a single germ layer) do not exist in isolation. Multiple lineages must interact in an exquisitely coordinated manner from the earliest stages of development and throughout life for the organism to grow and function. The programs of organogenesis that constitutively unfold in the developing human reinforce this notion. For example, using hESCs to model the human epiblast, it was observed that, likely from the earliest stages of gastrulation and continuing throughout embryogenesis, vascular and neural systems co-pattern and promote the differentiation of each other in an obligatory manner (25). If either lineage is eliminated, development of the other regresses: neurovascular patterning is compromised and autonomic nervous system differentiation is impaired, setting the stage for pathological consequences (e.g., the appearance of a Hirschsprung's phenotype).

We are coming to recognize that disease states as well cannot be viewed as emanating from the misbehavior of a single cell type. A case in point is our growing sophistication about the root pathophysiological processes underlying amyotrophic lateral sclerosis (ALS). Other than Parkinson's disease, there have been few neurological conditions in which stem cell researchers have been more focused on the dysfunction of, and the need to replace, a single cell type; in the case of ALS, it is the ventral horn spinal motor neuron $(\mathrm{MN})$. However, recent NSC transplant studies into the SOD $1^{\mathrm{G} 93 \mathrm{~A}}$ mouse model of ALS reinforced what had been a growing sense in the neuromuscular field that astrocyte interaction with $\mathrm{MNs}$ is a key pathological process that requires remediation (26). NSCs proved therapeutic in this case not because they replaced MNs but rather because they inhibited the animal's own NSC-derived production of toxic astrocytes, replaced them with normally functioning astrocytes (which now produced neuroprotective, neurotrophic, and anti-inflammatory factors), and increased the population of neuroprotective gray matter oligodendrocytes.

Hence, pure cell populations may not be the best way to recapitulate a "disease in a dish". More broadly, when contemplating the use of stem cells for transplant-mediated cell-based therapies in the nervous system (but likely extrapolatable to other systems), it is critical to remember 


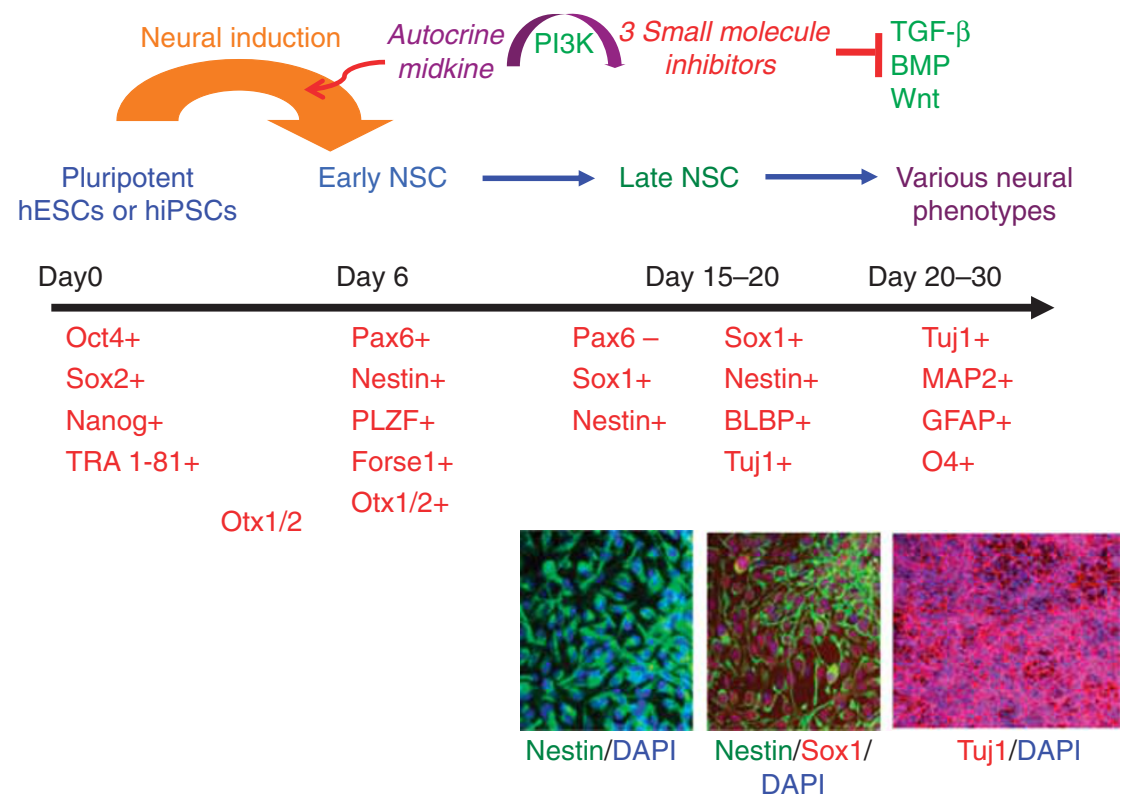

Figure 5. The process of differentiation from a pluripotent human stem cell to a cell committed to neurectodermal lineage. Modified from reference (27). BMP, bone morphogenetic protein; DAPI, 4,6-diamidino-2-phenylindole; hESC, human embryonic stem cell; hIPSC, human induced pluripotent stem cell; NSC, neural stem cell; TGF- $\beta$, transforming growth factor- $\beta$.
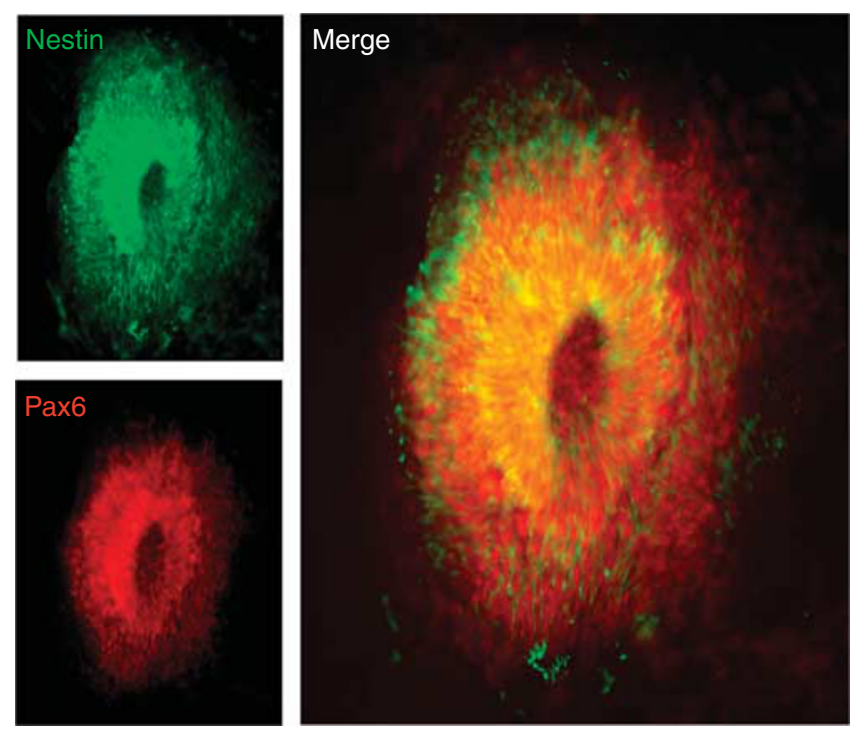

Figure 6. A three-dimensional neural tube (an "organoid") assembled in a dish from stem cell-hPSC-derived primitive hNSCs. Modified from reference(27). A structure like this may help to understand the cellular and molecular basis of diseases affecting fundamental neural development. hPSC, human pluripotent stem cell; hNSC, human neural stem cell.

that: (a) insults likely injure multiple systems, not just neural -e.g., hypoxia-ischemia and stroke, trauma, infection, inflammation-mandating that repair and therapy similarly address multiple lineages; (b) the health or function of one cell-type may be dependent on another cell-type; and (c) ultimately, regenerative strategies reinvoke developmental strategies.

\section{WHAT IS THE RIGHT METRIC TO PROFILE?}

Figure 4 illustrates the "pyramid" of increasing cellular complexity in the behavior of stem cell derivatives, posing the question of where should a translationally oriented stem cell biologist focus when trying to model and understand a disease process in order to develop therapeutic interventions.

Although genomic and transcriptomic analysis has been the mainstay of molecular profiling of stem cells and their derivatives, there is a growing appreciation that the genome and gene expression alone is likely not a sufficient metric. Indeed, the inability of genome-wide association studies (GWAS) to provide clarity for many neurological conditions over the past dozen years reinforces the recognition that such profiling alone provides an incomplete story. Profiling the proteome is being recognized as more informative because it represents the integration of many impinging and interacting genetic and epigenetic forces and determines the actual action of the cell. More precisely, it is not just the presence or absence of a protein that is critical but rather the protein's state of posttranslational modification (PTM). Of these PTMs, phosphorylation is likely most central to stem cell behavior. Cellular signaling is largely controlled by protein phosphorylation. Hence, changes in protein phosphorylation networks are pivotal to understanding how cells respond to stimuli and progress from one differentiation state to another. It is that PTM that often drives other PTMs. Indeed, for many critical genes, using the relative abundance of its mRNA is actually misleading in terms of predicting phospho-protein abundance. In a recent large-scale (phospho)proteomic analysis of differentially regulated phosphorylation events critical to complex stem cell actions (27), the relative transcript 
abundance and phosphorylated protein abundance did not correlate $\sim 50 \%$ of the time. In some cases, mRNA predicted the opposite of the actual (phospho)protein abundance as experimentally measured-particularly for genes that differed significantly between hESCs and their neurectodermal derivatives (For neurodegenerative diseases, such PTMs as ubiquination for the handling of folded proteins are coming to be recognized as pivotal).

Although protein kinase-driven signaling networks are critical for controlling stem cell fate, as illustrated in Figure 5, the field is increasingly recognizing that a cell's actual metabolic state is most predictive of its disease relevance. Hence, the "metabalome" is being profiled. It should be noted that, because of the inherent heterogeneity that emerges within even initially uniform populations of pluripotent and multipotent stem cells (a fundamental stem cell property), "single cell 'omics" is emerging as the preferred method for molecular profiling. Powerful computational biology is subsequently applied to these multiple single cellderived data to enable a coherent molecular signature to emerge.

Because human function is not best represented by stem cell derivatives in isolation or in two dimensions in cultured monolayers, more frequently stem cell biology is being analyzed in terms of its connections to other cells ("connectome") and in three dimensions that attempt to emulate the structure of the organ of interest ("organoids" or, for the central nervous system (CNS), "mini-neural tubes" (Figure 6) and "cerebroids") $(26,27)$.

\section{WHAT IS A CLINICALLY MEANINGFUL PREDICTOR?}

Not surprisingly, hiPSCs have made their greatest impact in studying monogenic diseases in terms of helping to reveal clinically relevant pathophysiology; an investigator already knows upon which biochemical pathways, gene products, and cell types to focus (30-40). However, the greatest challenge for "Disease-in-a-Dish Modeling" has been to offer similar insights into the molecular pathogenesis of complex, polygenic, multifactorial disorders for which the underlying pathophysiology and relevant genes, cell types, and molecular mechanisms are unknown. Many pediatric neurological conditions fall into this category (e.g., neuropsychiatric conditions; autism; developmental delay; dyslexia; certain cancers; metabolic derangements; most syndromes, dysmorphologies, and dysgenetic conditions). Although there has been no difficulty in making hiPSCs from patients with these disorders, the struggle has been to go beyond phenotypic description to discerning underlying molecular mechanisms.

Recently, we were able to make progress in using hiPSCs to discern the molecular etiology and pathophysiology of a psychiatric disorder, a "poster child" for such disorders (41). We started from the knowledge that one-third of bipolar disorder (BPD) patients are lithium-responsive for entirely unknown reasons. We reasoned that, were lithium's target to be identified, then BPD's pathogenesis might be unraveled.
Using proteomic techniques, we identified and mapped the molecular "lithium-response pathway," which we determined governs the phosphorylation of a protein called "CRMP2" ("collapsin response mediator protein-2"), a cytoskeleton regulator we found to be particularly critical for dendrite and dendritic spine morphogenesis-hence, a neural network modulator. Although "toggling" between inactive (phosphorylated) and active (nonphosphorylated) CRMP2 is physiologi$\mathrm{cal}$, the "set-point" in lithium-responsive BPD patients, we found, is abnormal (an observation validated in animal models, single neuron function studies, and in actual human brain specimens). Lithium (and other pathway modulators) normalize that set-point. Hence, BPD is a disorder not of a gene but of the posttranslational regulation of a developmentally critical protein (or "gene product"). As a result of this abnormality, the morphology and function of dendritic spines is abnormal, and hence, neural circuitry is impairedsignaling is decreased, less complex, dysfunctional. Such knowledge should enable better mechanistically based treatments and bioassays for reversing the morphogenic abnormalities and restoring function. Instructively, lithium was our "molecular can-opener" for "prying" intracellularly into the hiPSC to reveal otherwise inscrutable pathophysiology in this complex polygenic disorder. This approach, we believe, might be used for enabling hiPSCs to crack the mysteries of other "opaque" disorders. In other words, with regard to disease modeling in general, to quote our Discussion from that paper (41), this study suggested a strategy for merging hiPSC technology with proteomics to discern underlying pathophysiological mechanisms in diseases in which causative genes, cells, proteins, and pathways are not well understood. If there exists an agent that is known to be functionally impactful even if its molecular mechanism-of-action is uncertain (like lithium in BPD) - such an agent may allow an investigator to probe otherwise unknown intracellular signaling by identifying that agent's target and then reconstructing the regulatory molecular routes upstream and downstream of that target with an eye toward mapping underlying pathogenic pathways and identifying more specific drug targets for the development of safer, cheaper, or more effective pharmacotherapeutics. In this way, hiPSCs may be used in the most challenging diseases not only to reflect phenomenology and a phenotype, but also to identify underlying molecular mechanisms. Another important insight emerged from these studies: most neurological disease is likely not due solely to the death of neurons (as translational neural stem cell biologists have believed) but rather to the disruption of neural circuits. The goal of regenerative medicine for the nervous system is likely not our heretofore held overly simplistic view of replacing lost neurons and enhancing neurogenesis but rather restoring disrupted or impaired neural networks.

Intriguingly, as illustrated by the above-described studies, the ability to use stem cell biology to generate neurons from the peripheral blood (the starting cell for many of our hiPSCs) rendered an easily accessible tissue capable of potentially 


\section{Review $\mid$ Snyder}

predicting a complex neural process (e.g., network formation and function) in the inaccessible CNS.

\section{PREVENTION/INTERVENTION}

As noted above, the value of being able to predict and model a disease is, following that, to be able to do something about it. The most effective intervention is to prevent or attenuate the condition.

To use the example described above, we have devised highthroughput screening assays based on diminishing the proportion of inactive CRMP2 in order to identify more specific and less toxic drugs that might be used in lithiumresponsive $\mathrm{BPD}$ and perhaps other neurological conditions that pivot on cytoskeletal pathology.

The fact that many cancers are initiated by abnormalities in stem cell differentiation suggests that drugs may be discovered that can suppress or even preempt the development of certain neoplasm if the at-risk patient population can be identified at birth.

We demonstrated that exogenous hNSCs (42), implanted relatively non-traumatically in utero into the germinal zonelined cerebral ventricles of fetal monkeys (43), could participate in cerebrogenesis, creating chimeric brains (including a chimeric pool of "adult" NSCs that will participate in homeostatic processes and repair throughout life $(1,5,8,9))$. This observation suggested to us that even a disease process that may not find expression until birth, childhood, or even adulthood might be "diluted" through the presence of normal NSC-derived cells participating in the generation of the brain. For example, recognizing that treatment of a neurologicl a disease is most impactful when started as early as possible (ideally premorbidly) and that, for most monogenic lysosomal storage disorders (LSDs) (which can be diagnosed prenatally) even a relatively small amount of enzyme can restore normal metabolism, might such conditions be prevented by an NSC-mediated fetal intervention (44)? If the disorder to be so "diluted" during cerebrogenesis was one that does not find expression until adulthood (e.g., Huntington's disease) could an invariably lethal condition be converted to a less incapacitating one? Could all disease ultimately fall under the purview of the pediatric translational stem cell biologist?

The advent of genome editing techniques, such as zinc finger nucleases, TALENS, and, most particularly, CRISPR/ Cas9, has made feasible the editing of "stem cells" in the human blastocyst such that lethal genes are "repaired" or

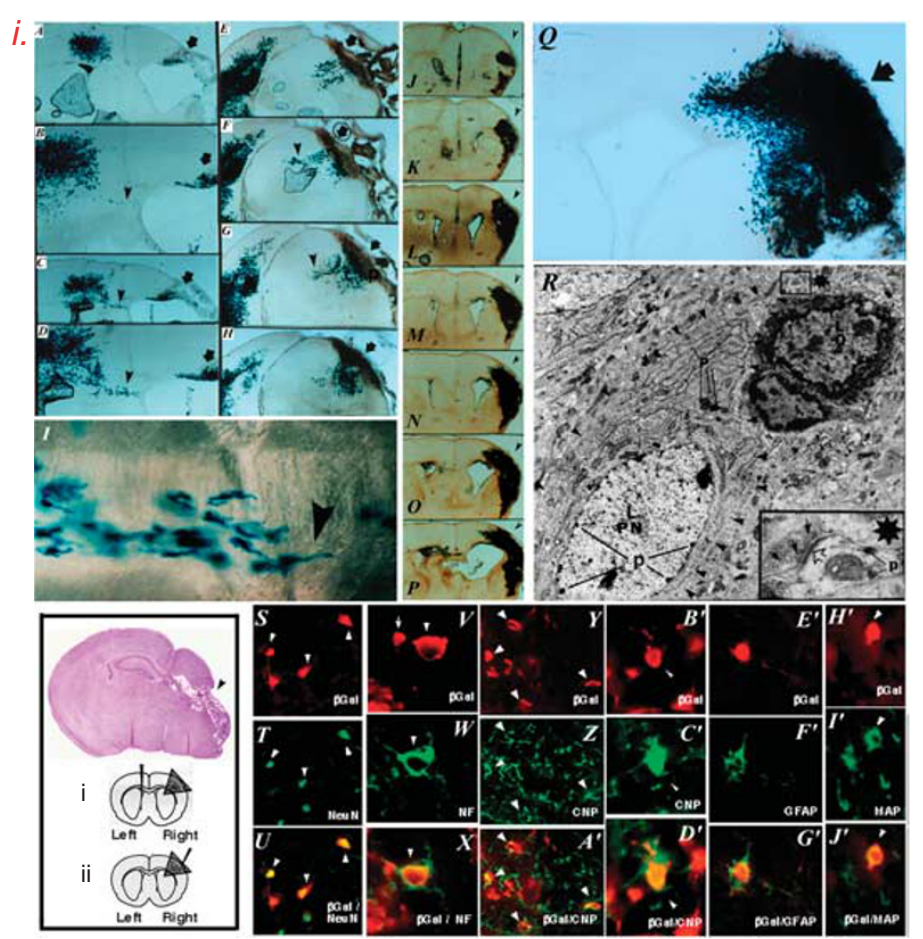

IV. $\quad \underline{\text { Intact }}$ left hemisphere

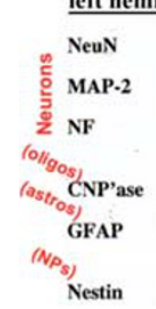

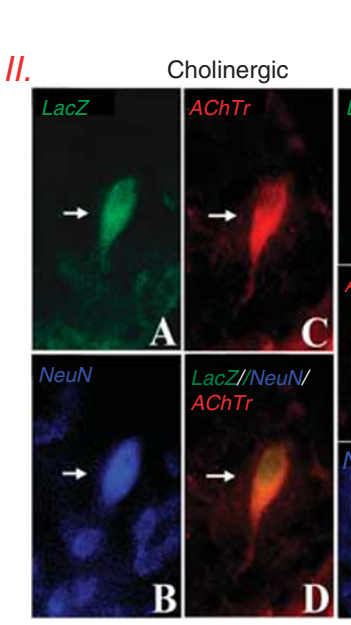

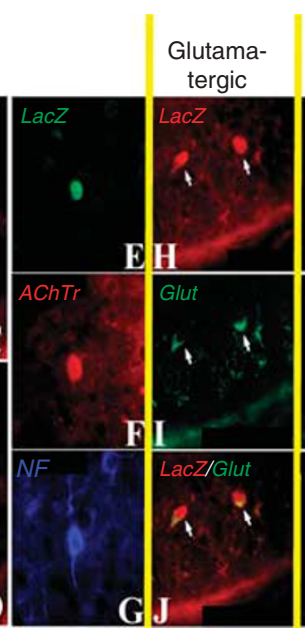

GABA ergic

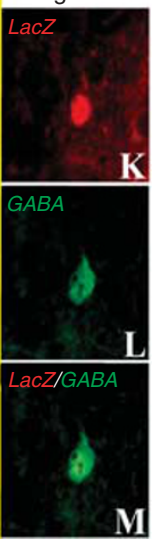

III.
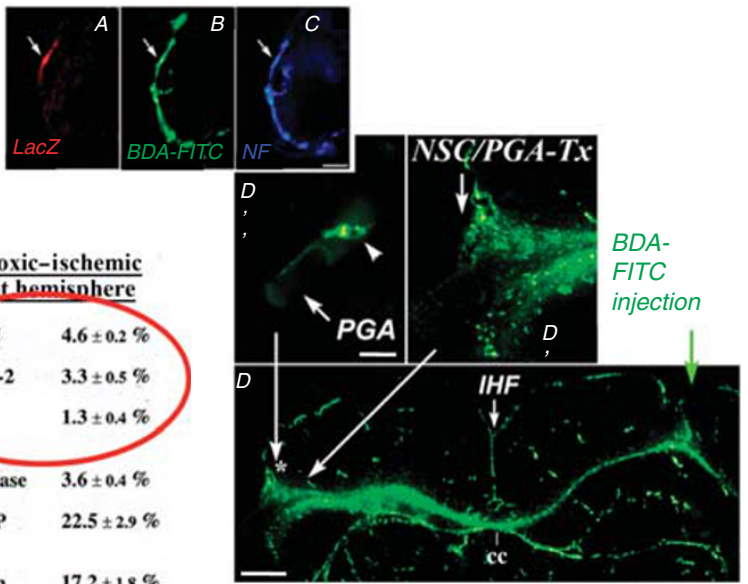


\section{Stem cell biology and regenerative medicine $\quad$ Review}

eliminated. This approach was recently successful in correcting a heterozygous mutation in a gene, $M Y B P C 3$, known to cause a cardiomyopathy with a high lethality risk (45). Although the mutation was corrected in human preimplantation embryos with precise CRISPR-Cas9-based targeting accuracy and high homology-directed repair efficiency, the mutant allele (which was paternal) was predominantly repaired using the homologous wild-type gene (which was maternal) and not the synthetic DNA template, suggesting that an endogenous, germline-specific DNA repair response was triggered by the intervention. Hence, as successful as this experiment was, questions regarding mechanism still linger. However, these technical hurdles will likely be circumvented leaving stem cell-based interventions in the preimplantation embryo as a feasible option for negating or minimizing that negative impact of a gene.

All of these "preventative" interventions are suffused with ethical considerations and quandaries. Even if the intent is to insure a good outcome for children by suppressing the expression of malevolent genes, and even if there are sufficient safeguards instituted to screen out practitioners with nefarious intent, do we have a complete enough grasp of the complexity of gene and cellular networks? Do we know how the altering of one gene or neural circuit will change the expression of other genes or circuits in unintended ways? Are we wise enough to know which genetic manipulations should enter the germline (a likelihood of the genetic manipulation is done at the time of fertilization); in other words, which changes should be passed on to all progeny of those parents? However, given the dictum that "good ethics start with good data", rigorous preclinical research is the only way to answer these questions.

\section{PROTECTION}

If one cannot prevent a disease state, then the hope would be to protect those cells and circuits "at risk" for dysfunction

Figure 7. Migration to and altered differentiation of transplanted murine neural stem cells (NSCs) within the ischemic area of a newborn mouse brain subjected to unilateral hypoxic-ischemic ( $\mathrm{HI}$ ) injury via unilateral carotid artery occlusion followed by hypoxia (the Rice-Vanucci model). Modified from References $(7,8,65)$ (I.) (INSET The two paradigms employed for site of transplantation of NSCs in relation to the infarct (arrowhead); transplants were performed 3 days post-HI which was experimentally induced at postnatal day 7 [P7]. Brains were analyzed at adulthood (at least 2 months of age. Coronal $\mathrm{H} \& \mathrm{E}$ section indicates the appearance of an untreated infarcted region. (A-I) Robust migration by lacZ-expressing NSCS (blue) from their injection site in the left contralateral ventricle (as per Paradigm i in the Inset) to and throughout regions of ischemic damage (arrows). (A-H) Semiserial sections throughout the cerebrum, rostral to caudal. Xgal+ (i.e., blue LacZ-expressing) donor-derived cells are seen migrating through the corpus callosum and commissures (arrowhead) and into and throughout the ischemic right hemisphere, drawn by tropic signals. A representative Xgal+ cell (blue) in the corpus callosum is magnified in (I), revealing a classic migratory leading process (arrowhead). When NSCs are injected directly into the ischemic region as per Paradigm ii of the Inset, they never migrate toward the intact side but rather integrate throughout the infarcted cerebrum (J-P); a representative stably engrafted region is magnified in (Q) 2 months posttransplant. Ultrastructural (R) and immunocytochemical (S-J') analyses show the NSCs to yield neurons and oligodendrocytes, the two cells types most severely damaged by HI. (R) The Xgal precipate forms electron-dense precipitates "p" localized typically to the nuclear membrane and in cytoplasmic organelles like the endoplasmic reticulum). Three donor-derived cells are seen. The two small cells are Xgal-labeled oligodendroglia (LO). These are situated next to a large labeled pyramidal neuron (LPN) (outlined by small arrowheads). At the top of the apical dendrite (blocked area with ${ }^{*}$ shown at higher power in the bottom right inset), one can see the donor-derived PN receiving synaptic input from the host. ( $p$ indicating precipitate confirms that the postsynaptic region is donor derived). (S-J'). Donor-derived, lacZ-expressing cells are identified by anti- $\beta$ gal immunofluorescence (Texas red, top row) and neural cell-type-specific markers are visualized by fluorescein isothiocyanate (FITC; middle row). Double labeling, seen as a yellow/orange fluorescence, is observed by dual bypass filter microscopy (bottom row). Donor-derived cells within the infarct express the mature neuronal markers NeuN and neurofilament (NF) (donor-derived neurons indicated by arrowheads, non-neuronal engrafted cell indicated by arrow); the oligodendroglial marker CNPase (donor-derived oligodendrocytes indicated by arrowheads); and the mature astrocytic intermediate filament glial fibrillary acidic protein (GFAP). (H'-J') Even donor-derived cells as much as $1 \mathrm{~mm}$ from the infarct on the ipsilateral side can be influenced to differentiate into neurons (lacZ/MAP-2+ cells (arrowheads). (II.) The donor-derived neurons have the ability to differentiate into cells with the expected range of cortical neurotransmitter types-cholinergic (A-D) and (E-G), glutamatergic (H-J), and GABAergic (K-M). (III.) This series of panels show that NSCderived neurons are capable of sending long-distance transcollosal connections from the infarcted cortex to appropriate targets regions in the intact contralateral hemisphere. To confirm that long-distance processes projected from the injured cortex into host parenchyma, a series of antegrade and retrograde tract tracing studies were performed on the donor-derived $\beta$ gal+ neurons, one of which is illustrated in (D-D"). To confirm that such long axons were derived from the injured, transplanted regions, BDA-FITC was implanted into the opposite (left) intact hemisphere within the target region of such transcallosal axons (at 8 weeks following implantation into the infarction cavity) ( $n=10$ ), in order to monitor retrograde transport of the tracer back to their source in the right hemisphere. Axonal projections (labeled green with fluorescein under an FITC filter) are visualized (via the retrograde transport of BDA) leading back to (across the interhemispheric fissure (IHF) via the corpus callosum (cc)) and emanating from cells within the damaged engrafted cortex ad penumbra (seen at progressively higher magnification in (D') (region indicated by arrow to (D)) and (D”) (region indicated by arrow and asterisk $\left(^{*}\right)$ in (D)). In (D"), the retrogradely BDA-FITC-labeled perikaryon of a representative neuron is well visualized. That such cells are neurons of donor derivation is supported by their triple labeling (A-C) for lacZ (Bgal) (A), BDA-FITC (B), and the neuronal marker NF (C); arrow in (A-C) indicates the same cell in all three panels). Scale bars: (A-C), $30 \mu \mathrm{m}$; (D), $500 \mu \mathrm{m}$; (D”), $20 \mu \mathrm{m}$. (IV.) The Table indicates that the same NSC clone yields no neurons in an intact cortex and $<1 \%$ oligodendrocytes, the normal developmental profile of the post-cerebrogenic adult mammalian cortex. However, in the "postdevelopmental" infarcted cortex, new neurogenesis occurs. Therefore, HI must create an altered milieu to which the NSCs respond by shifting their differentiation fate toward one of cell-type compensation. These data have been replicated using human NSCs. The table reveals another interesting finding. "New neurons" are not the only cell type that the multipotent NSCs yield in the injured cortex. As suggested by the immunostaining in I-[Y-D'] and the EMs in I-Q, they quadruple the number of oligodendrocytes, double the number of astrocytes (GFAP+ cells, E'-G'), and triple the number of undifferentiated neural progenitors (Nestin+ cells), suggesting that the NSC is "attempting" to reconstitute the entire milieu of the damaged cortex, including the non-neuronal "chaperone" cells that have an important role in functional recovery -and, indeed, may be the most important cell type clinically. These patterns of migration, integration, and differentiation are not seen if NSCs are transplanted after 10 days post-HI. 


\section{Review | snyder}

and/or death. Indeed, most stem cells actually do exert this powerful action-dubbed the "Chaperone Effect" and discovered by us somewhat serendipitously (46-50). It remains the attribute responsible for most therapeutic successes recorded to date for any stem cell in any organ system with very few exceptions. Like much of the history of the translational stem cell field, the Chaperone Effect (sometimes called stem cell's "paracrine action") was an insight forced upon us by the data while trying to achieve something entirely different. In a series of animal models of neurological disease, we were attempting to replace defective neurons-A9 nigral dopaminergic neurons in rodent and monkey models of Parkinson's disease $(47,48)$, cortical neurons in mouse models of LSDs $(1,44,46,51)$ and perinatal asphyxia $(7,8)$, MNs in murine models of ALS (26), long projection neurons in spinal cord injury $(49,50,52)$, and hippocampal neurons in traumatic brain injury $(53,54)$. In virtually every case, we did see histological, biochemical, and functional improvement in the respective models-but, to our chagrin, it was not because we had replaced the targeted neurons but rather because we had rescued the animal's own neurons from dysfunction and death. These actions by exogenous NSCs upon host pathological niches were mediated by secreted factors (trophic $(26,46-48,53,54)$, protective $(26,46-48,53,54)$, anti-inflammatory $(7,26,46)$, antiscarring $(7,50)$, pro-angiogenic (7)) and cell-cell contact (gap junctions) (49). Subsequent studies by others have implicated intercellular communication via released exosomes (55) and tunneling nanotubes (56). Interestingly, NSCs (and most somatic stem cells) possess an inherent pathotropism $(4,6-8,26,42,48,53,54,57)$-i.e., a chemoattraction to areas of pathology (Figure 7)-which is mediated by precisely the inflammatory cues (6) the NSC will subsequently suppress.

Although we initially regarded the above-described observations as the "consolation prize" for having misjudged the ability of exogenous NSCs to respond to cues and integrate into a pathological system, we soon came to recognize that the "Chaperone Effect" actually was the prize-particularly when the observation was replicated by numerous other investigators using a wide variety of stem cell types, organ systems, and disease models. We came to realize that the NSC was simply pursuing one of its teleological imperatives-to promote homeostasis (Figure 1) - and that a more careful examination of our earlier data would have predicted that the NSC was allocating progeny in a manner that reconstitutes the system with neural cells of the multiple sub-types that comprise the niche-in the right ratios and performing their intended functions (for example, see Figure 7). Neurons, in fact, are normally a minority cell type in the CNS. Preservation of function, which pivots not on neurons in isolation but rather on neurons in networks, is often mediated by the nonneuronal population, particularly astrocytes. Indeed, diseases often result not solely from neuronal impairment but also from a failure of non-neuronal "chaperone cells" to "do their job" or, in some cases such as ALS, actively sabotaging neural integrity (26,57-59). Indeed, in the set of experiments illustrated in Figure 7, the NSCs served as "reporter cells": genetically tagged clonal plastic-responsive multipotent stem cells that "interrogated" the functional responses and molecular characteristics of a particular developmental or diseased milieu and could then be assayed by investigators both in vivo and in vitro (8). What they reported back was an appreciation that has influenced our work (and that of many others) for two decades: (a) the concept of a dynamic crosstalk between implanted stem cells and the injured/degenerating microenvironment $(7,26)$, (b) that stem cells exert their actions via multiple mechanisms targeting multiple pathological processes $(26,46)$, and (c) that stem cells may, in fact, be most effectively used in the context of synergistic multidisciplinary strategies-including as adjuncts to tissue engineering (in brain and spinal cord) (7), gene therapy $(1,42,60)$, and pharmacology (46). More on this below. The manifestations of most neurological diseases are ultimately the expression of a number of interacting and mutually compounding pathogenic processes; hence, multiple therapeutic targets must be addressed. The NSC is well suited for this challenge because of its multiplicity of actions. Indeed, the greatest efficacy observed using NSCs in experimental models of neurological disease has come when we harness and exploit its above-described multimodal therapeutic actions.

In short, this so-called Chaperone Effect has become a powerful force within the stem cell field and probably is the most tractable near-term application for stem cells against a variety of neural disorders, with extrapolation (as we see in this issue) to stem cells and diseases of other organ systems (including heart, muscle, pancreas, lung, gut, bone, etc.).

\section{RESTORATION}

When we have failed to predict and hence avert a disease process, or have acted too late to protect and rescue the cells from demise and dysfunction, our patients ask us to restore lost function. In confronting this challenge, we are forced also to deal with the "hype" and high expectations that attended the public's introduction to the stem cell field. How well have we done in this first quarter century, and how much further do we need to go? Based on its position on my list in Figure 4, not far enough, and we have an arduous journey ahead.

The best documented instances in the regenerative medicine literature where function has actually been restored in preclinical models are pathologies resulting from an inherited lysosomal enzyme deficiency as seen in pediatric LSDs $(1,44,46,51,61)$. In such cases, as little as $2 \%$ of normal lysosomal enzyme levels, constitutively produced and secreted by an implanted exogenous normal cell (even without having been genetically engineered) will restore normal metabolism to a deficient cell when endocytosed via its mannose-6phosphate receptor. If instituted early enough in the life of the patient, before there is significant irreversible death of a critical number of neural cells, function can be restored. Similarly, in cases due solely to the cell autonomous absence of myelinating cells-e.g., in the shiverer mutant mouse $(5,62,63)$, which may model the rare pediatric disorder 
Pelezius-Merzbacher disease (64) but does not represent most demyelinating or dymyelinating disorders (61)-replacement of NSC-derived oligodendrocytes can restore function.

Even these examples presume early intervention and actually fall in the gray zone between "Protection" and "Restoration". And restoration of function may not be permanent. With time-and the growth of the child (hence an increase in the number of mutant cells, overwhelming the transplanted normal cells) and the inevitable senescence of the donor cells-the pathological process resumes and symptoms reappear. This situation might be remedied by re-implantation periodically of new cells; however, this approach has yet to be tested. For example, could the first cell graft immunosensitize the patient to a repeat exposure to those cells? If autologous hiPSCs were used, would that risk be averted?

The above-described conditions, however, are not the cases with which clinicians are typically confronted when asked to "restore function". Most patients who come to us for relief have been suffering from the consequences of disease or injury for a very long time and request treatment long after the pathophysiological process has become entrenched. They have been in wheel chairs for years. Restoring function to chronic disease states is regenerative medicine's major challenge and has long been its "third rail". Virtually every therapeutic success recorded in the literature has been following early intervention during the acute or subacute phase of the insult where protection, anti-inflammation, antiscarring actions may still have an impact-for example, rescuing the penumbral region of a stroke before it becomes part of the necrotic core. We have been largely ineffectual in addressing neurological conditions of long-standing.

There are a few approaches that might be envisioned. The first might be to recreate the acute or subacute milieu in the chronic microenvironment. Work has been carried out to characterize the molecular differences-from the "viewpoint" of the NSC-between a chronically injured brain and an acutely injured brain (8). When the same "reporter" NSC clone is exposed to two similar injured brain preparations that differ only in the duration of time following an ischemic insult, the acute brain preparation promotes an upregulation in the NSC of molecular pathways mediating proliferation, migration, differentiation, and antiapoptosis, while the chronic brain preparation suppresses these pathways and instead promotes exit from the cell cycle, inhibition of migration, diminished differentiation, and pro-apoptosis. To use an analogy, if the acute/sub-acute environment is like the "accelerator of a car", then the chronic environment, from the vantage point of the NSC, is like the "break". Hence, one strategy might be to engineer the niche to express "acute" signals to "fool" both endogenous and exogenous NSCs that an injury is "fresh" $(63,64)$. Similar strategies can be carried out to promote migration by using benign non-inflammogenic mimics of SDF1 $\alpha$, an inflammatory chemokine that is robustly expressed in the acutely injured environment and also has potent chemoattractant properties (6).
However, there are limitations to the approach of simply attempting to alter the molecular signature of the chronically injured niche. In chronic CNS injury, not only may we have missed our "window of molecular opportunity" but also there are additional obstacles and challenges that have been imposed, e.g., scarring, neural reorganization, disruption of vascular patterns, muscle atrophy, depletion and displacement of endogenous neural progenitor cells, neural cell death, encephalocoeles and syrinxes, cortical atrophy, ventriculomegaly, myelin loss, altered extracellular matrix, contractures, etc. These problems are not amenable simply to extending strategies that worked in the acutely and subacutely injured CNS into later time periods at higher doses and for longer periods of time. Indeed, many of these problems are no longer simply "neural". These challenges require entirely new paradigms-for example, strategies to create new circuitry and alternative routes to end organs; promoting the assumption of function by other control centers; reorganization of pathways from higher centers to MNs, perhaps through the re-engagement of intraspinal motor programs that existed in infancy but became subjugated by higher centers (50,52); reorganization of cortical maps; filling or creating detours around cysts and scars; insertion of stimulators and pattern generators; and creating threedimensional implantable mini-organs or CNS regions. It is clear that the simple transplantation of stem cells will not circumvent these challenges or enable these strategies. It will require multi-modal approaches, including bioengineering solutions that will engage the use of synthetic biocompatible materials $(50,52)$, multiple cell types (26), genetic manipulation $(65,66)$, stimulation, rehabilitation, and other "workarounds".

\section{CELL REPLACEMENT}

Although replacing missing or lost neural cells has been the longest standing goal of translational stem cell biology and regenerative medicine-indeed, the field's raison d'être-it has been its most elusive. In the discipline's infancy, it did not appear that it would be so difficult. We found that undifferentiated NSCs, when implanted into the developing cerebellum would become appropriate neural cell types in a region and developmental cue appropriate manner $(1,42,67)$. When the same NSCs were placed into a region of adult mouse cortex in which pyramidal neurons had been induced to undergo apoptosis, they differentiated into pyramidal neurons in that region (and only in that region), as if responding to recapitulated developmental cues (4). When implanted into an ischemic brain, the same clone of NSCs would spontaneously attempt to reconstitute the region with neurons, astrocytes, oligodendroglia, and even new NSCs in the appropriate ratio (8). When NSCs were implanted into the dopamine-depleted nigrostriatal path of monkeys, a certain proportion constitutively become dopaminergic (47). All of this was achieved without explicit preinstruction of the NSCs. Such observations by us and others lulled the field into an inappropriate nonchalance about the intricacies of neural 
Figure 8. Potential actions of stem cells in neurological conditions.

differentiation and commitment. "The cells know what to do" became an overly naive aphorism of the field. Although it is true that environmental cues will bias undifferentiated NSCs toward an appropriate lineage, consummation of that commitment to the point of making proper connections without making inappropriate connections requires extremely precise molecular signaling. Not just in the nervous system but in all organ systems, we have come to realize that the progeny of stem cells are immature versions of the cells we desire. Continued proper maturation and fine-tuning of regional identity requires providing precise developmental signals (including in three dimensions and likely in combination with mechano-signaling). And some of those cues have not yet been completely elucidated by developmental biologists. Furthermore, some neural progenitors may already have predetermined specifications based on cues imprinted at gastrulation and cerebrogenesis (68). For example, hNSCs derived from human PSCs have a predilection to give rise to dorsal cortical glutamatergic and GABAergic interneurons. To instruct them to become A9 midbrain dopaminergic neurons, one must ventralize them with sonic hedgehog, instruct them to become midbrain with FGF8, and then turn them into floor plate via Wnt inhibition (69). Only then will they robustly become A9 dopaminergic neuronal precursors that, when implanted into an MPTPlesioned monkey, will produce a sufficient amount of dopamine to ameliorate Parkinsonian symptoms.

Needless to say, we have gone past the point where we expect non-neurectodermal-derived cells to become neural cells in the absence of intense genetic manipulation. Mesenchymal stromal cells and umbilical cord blood stem cells will not spontaneously become neural cells, for example. Indeed, recent evidence suggests that, when such non-neural cells. administered intravascularly , have an impact on a neurological problem, it is usually because their actual target has been in the peripheral circulation - e.g., lung and/or spleen, organs that then elaborate bioactive factors (often anti-inflammatory) that circulate into the brain (or other organs) and have an effect (71). Alternatively, the cells may block the elaboration of toxic factors from those peripheral organs (72). We do, however, need to be vigilant that cells from one organ system placed in a heterotopic and nonhomologous region to perform non-homologous functionse.g., mesenchymal stromal cells directly into an inflamed brain-do not create mischief by nevertheless playing out their normal biological imperatives-for example, laying down connective tissue, which can form masses, in response to inflammatory cytokines (72).

\section{CONCLUSIONS}

The translational solid-organ stem cell field-Regenerative Medicine-is no longer "a shiny new object". It is over a quarter-century old. There is great promise but also, we know, a great deal of "non-headline-grabbing" work that needs to be carried out.

Using stem cells to model diseases for the purpose of drug discovery and using transplanted stem cells for altering a toxic milieu are probably more near-term applications than is reconstructing whole regions of the brain-although the use of biomaterials and substrates and three-dimensional printing might make that task easier if we can get a handle on the proper sequence of developmental signals.

And, after all, Regenerative Medicine is, at the end of the day, "translational developmental biology". Working in concert with the developmental processes and imperatives, and absolutely not working at cross-purposes to them, is the only way to make a positive impact.

Stem cells are just one weapon in a therapeutic armamentarium. Diseases are complex; hence the treatments will need to be complex and multifaceted. Stem cells are ideally suited to be the "glue" that holds these multiple approaches together (Figure 8). The question remains, how best to orchestrate them all. We may need multiple cell types to reconstruct a niche. With that in mind, cell replacement for the nervous system should not be construed as solely "neuron" replacement. The repletion of functional glia and even microglia and vascular endothelium may be critical. Protection of established circuits may be as important-and more tractable-than establishing new ones, given the complexities of early development. Diseases are dynamic. Even for a single malady, the acute, subacute, and chronic phases may all have different needs.

One of the largest looming obstacles to the effective therapeutic use of stem cells remains the fact that, for most diseases, we frankly do not really know "what needs fixing". What needs to be altered to reverse autism or schizophrenia or Alzheimer's disease? For that matter, can we truly answer that precisely for hypoxic-ischemic injury or stroke? And even when we believe we know what should be repaired or replaced, the story becomes more complex-witness the changes in our thinking regarding ALS. For Parkinson's disease, dopamine replacement does not halt progression of the disease. 


\section{Stem cell biology and regenerative medicine $\quad$ Review}

When one does have encouraging preclinical data, what should be the criteria for launching a clinical trial in the stem cell field? I have personally used the following criteria since the inception of the Regenerative Medicine field: The approach, when subjected to critical scrutiny, must make biological and developmental sense with regard both to the known pathophysiology, pathogenesis, and treatment gaps of the disease to be targeted as well as the known biology of the cells. A plausible mechanism of action must be known and a plausible therapeutic target for the cells for that particular disease identified. (For example, it was not recognized until recently that mesenchymal stromal cells and umbilical cord cells administered intravascularly for stroke were actually exerting their effect on the spleen and lung, never taking up residence in the brain; those stimulated organs subsequently elaborated brain-penetrant anti-inflammatory molecules secondarily $(70,71)$ ). Proof of concept in a predictive, wellcontrolled, authentic preclinical model must be compelling and better than standard of care. The intervention must be safe, produce no psychological or financial harm, and not jeopardize the institution of "better-proven" (even if standard) options. Good science informs good practice, which informs good business; so profit motive is never good reason to leapfrog over critical steps in rigor.

In summary, poised at the "end of the beginning" of the stem cell field, our "known knowns" have clearly increasedbut so have our "known unknowns", which are challenging. What is most daunting and concerning are the "unknown unknowns" that we know lurk ahead. But hopefully we have learned by this time to be vigilant, circumspect, self-critical, and humble.

Disclosure: The authors declare no conflict of interest.

\section{REFERENCES}

1. Snyder EY, Taylor RM, Wolfe JH. Neural progenitor cell engraftment corrects lysosomal storage throughout the MPS VII mouse brain. Nature 1995;374:367-70.

2. Becker AJ, McCulloch EA, Till JE. Cytological demonstration of the clonal nature of spleen colonies derived from transplanted mouse marrow cells. Nature 1963;197:542-454.

3. Snyder EY, Deitcher DL, Walsh C, Arnold-Aldea S, Hartweig EA, Cepko CL. Multipotent neural cell lines can engraft \& participate in development of mouse cerebellum. Cell 1992;68:33-51.

4. Snyder EY, Yoon CH, Flax JD, Macklis JD. Multipotent neural precursors can differentiate toward replacement of neurons undergoing targeted apoptotic degeneration in adult mouse neocortex. Proc Natl Acad Sci USA 1997;94:11663-8.

5. Yandava BD, Yandava BD, Billinghurst L, Snyder EY. Global cell replacement is feasible via neural stem cell transplantation: evidence from the shiverer dysmyelinated mouse brain. Proc Natl Acad Sci USA 1999;96:7029-34.

6. Imitola J, Raddassi K, Park KI. Inflammation's other face: directed migration of human neural stem cells to site of CNS injury by the SDF1a/ CXCR4-dependent pathway. PNAS 2004;101:18117-22.

7. Park KI, Teng YD, Snyder EY. The injured brain interacts reciprocally with scaffolds seeded with neural stem cells to reconstitute lost tissue. Nat Biotech 2002;20:1111-7.
8. Park KI, Hack MA, Ourednik J, et al. Acute injury directs the migration, proliferation, \& differentiation of solid organ stem cells: Evidence from clonal "reporter" NSCs. Exp Neurol 2006;199:156-78.

9. Reynolds BA, Weiss S. Generation of neurons and astrocytes from isolated cells of the adult mammalian central nervous system. Science 1992;255:1707-0.

10. Takahashi K, Yamanaka S. Induction of pluripotent stem cells from mouse embryonic and adult fibroblast cultures by defined factors. Cell 2006;126:663-76.

11. Takahashi K, Tanabe K, Ohnuki M, et al. Induction of pluripotent stem cells from adult human fibroblasts by defined factors. Cell 2007;131:861-72.

12. Gurdon JB. The developmental capacity of nuclei taken from intestinal epithelium cells of feeding tadpoles. J Embryol Exp Morphol 1962;34:93-112.

13. Kim K, Doi A, Wen B, et al. Epigenetic memory in induced pluripotent stem cells. Nature 2010;467:285-90.

14. Weinberger L, Ayyash M, Novershtern N, Hanna JH. Dynamic stem cell states: naive to primed pluripotency in rodents and humans. Nat Rev Mol Cell Biol 2016;17:155-69.

15. Choi J, Lee S, Mallard W, et al. A comparison of genetically matched cell lines reveals the equivalence of human iPSCs and ESCs. Nat Biotech 2015;33:1173-81.

16. Mezey E, Key S, Vogelsang G, Szalayova I, Lange GD, Crain B. Transplanted bone marrow generates new neurons in human brains. Proc Natl Acad Sci USA 2003;100:1364-9.

17. Johansson CB, Youssef S, Koleckar K, et al. Extensive fusion of haematopoietic cells with Purkinje neurons in response to chronic inflammation. Nat Cell Biol 2008;10:575-83.

18. Terada N, Hamazaki T, Oka M, et al. Bone marrow cells adopt the phenotype of other cells by spontaneous cell fusion. Nature 2002;416:542-5.

19. Vierbuchen T, Ostermeier A, Pang ZP, Kokubu Y, Südhof TC, Wernig M. Direct conversion of fibroblasts to functional neurons by defined factors. Nature 2010;463:1035-41.

20. Yang N, Zuchero JB, Ahlenius H, et al. Generation of oligodendroglial cells by direct lineage conversion. Nat Biotech 2013;31:434-9.

21. Qian L, Huang Y, Spencer CI, et al. In vivo reprogramming of murine cardiac fibroblasts into induced cardiomyocytes. Nature 2012;485:593-8.

22. Szabo E, Rampalli EY, Risueño RM, et al. Direct conversion of human fibroblasts to multi-lineage blood progenitors. Nature 2010;468:521-6.

23. Bhattacharyya A, Svendsen CN. Human neural stem cells: a new tool for studying cortical development in Down's syndrome. Genes Brain Behav 2003;2:179-86.

24. Song RS, Carrol JM, Acevedo L, Wu D, Liu Y, Snyder EY. Generation, expansion, and differentiation of human induced pluripotent stem cells (hiPSCs) derived from the umbilical cords of newborns. Curr Protoc Stem Cell Biol 2014;29:1C.16.1-3.

25. Acevedo LM, Lindquist JN, Walsh BM, et al. hESC differentiation toward an autonomic neuronal cell fate depends on distinct cues from the copatterning vascular cells. Stem Cell Rep 2015;4:1075-88.

26. Teng YD, Benn SC, Kalkanis SN, et al. Multimodal actions of neural stem cells in a mouse model of ALS: a meta-analysis. Sci Transl Med 2012;4: $165 \mathrm{ra} 164$.

27. Singec I, Crain AM, Hou J, et al. Quantitative analysis of human pluripotency and neural specification by in-depth (phospho)proteomic profiling. Stem Cell Rep 2016;7:527-42.

28. Lancaster MA, Renner M, Martin CA, et al. Cerebral organoids model human brain development and microcephaly. Nature 2013;501:373-9.

29. Clevers H. Modeling development and disease with organoids. Cell 2016;165:1586-97.

30. Ebert AD, Yu J, Rose FF Jr, et al. Induced pluripotent stem cells from a spinal muscular atrophy patient. Nature 2009;457:277-80.

31. Sun N, Yazawa M, Liu J, et al. Patient-specific induced pluripotent stem cells as a model for familial dilated cardiomyopathy. Sci Transl Med 2012;4:130ra47.

32. Itzhaki I, Maizels L, Huber I, et al. Modeling the long QT syndrome with induced pluripotent stem cells. Nature 2011;471:225-9.

33. Marchetto MC, Carromeu C, Acab A, et al. A model for neural development and treatment of Rett syndrome using human induced pluripotent stem cells. Cell 2010;143:527-39. 
34. Seibler P, Graziotto J, Jeong H, Simunovic F, Klein C, Krainc D. Mitochondrial Parkin recruitment is impaired in neurons derived from mutant PINK1 induced pluripotent stem cells. J Neurosci 31:5970-62011.

35. Byers B, Marchetto MC, Carromeu C, et al. SNCA triplication Parkinson's patient's iPSC-derived DA neurons accumulate alpha-synuclein and are susceptible to oxidative stress. PLoS ONE 2011;6:e26159.

36. Koch P, Breuer P, Peitz M, et al. Excitation-induced ataxin-3 aggregation in neurons from patients with Machado-Joseph disease. Nature 2011;480: 543-6.

37. Lee G, Ramirez CN, Kim H, et al. Large-scale screening using familial dysautonomia induced pluripotent stem cells identifies compounds that rescue IKBKAP expression. Nat Biotechnol 2012;30:1244-8.

38. An MC, Zhang N, Scott G, et al. Genetic correction of Huntington's disease phenotypes in induced pluripotent stem cells. Cell Stem Cell 2012;11:253-63.

39. Carvajal-Vergara X, Sevilla A, D'Souza SL, et al. Patient-specific induced pluripotent stem-cell-derived models of LEOPARD syndrome. Nature 2010;465:808-12.

40. Pasca SP, Portmann T, Voineagu I, et al. Using iPSC-derived neurons to uncover cellular phenotypes associated with Timothy syndrome. Nat Med 2011;17:1657-62.

41. Tobe BTD, Crain AM, Winquist AM, et al. Probing the lithium-response pathway in hiPSCs implicates the phosphoregulatory set-point for a cytoskeletal modulator in bipolar pathogenesis. Proc Natl Acad Sci USA 2017;114:E4462-71.

42. Flax JD, Aurora S, Yang C, et al. Engraftable human neural stem cells respond to developmental cues, replace neurons, \& expess foreign genes. Nat Biotechnol 1998;16:1033-9.

43. Ourednik V, Ourednik J, Flax JD, et al. Segregation of human neural stem cells in the developing primate forebrain. Science 2001;293:1820-4.

44. Lacorazza HD, Flax JD, Snyder EY, Jendoubi M. Expression of human betahexosaminidase alpha-subunit gene (the gene defect of Tay-Sachs disease) in mouse brains upon engraftment of transduced progenitor cells. Nat Med 1996;2:424-9.

45. Ma H, Marti-Gutirrez N, Park SW, et al. Correction of a pathogenic gene mutation in human embryos. Nature 2017;548:413-9.

46. Lee J-P, Jeyakumar M, Gonzalez R, et al. Stem cells act through multiple mechanisms to benefit mice with neurodegenerative metabolic disease. Nat Med 2007;13:439-7.

47. Redmond DE, Bjugstad KB, Teng YD, et al. Behavioral improvement in a primate Parkinson's model is associated with multiple homeostatic effects of human neural stem cells. Proc Natl Acad Sci USA 2007;104: 12175-80.

48. Ourednik J, Ourednik V, Lynch WP, Schachner M, Snyder EY. Neural stem cells display an inherent mechanism for rescuing dysfunctional neurons: evidence in aged mice. Nat Biotechnol 2002;20:1103-0.

49. Jäderstad J, Jäderstad LM, Li J, et al. Communication via gap junctions underlies early functional and beneficial interactions between grafted neural stem cells and the host. Proc Natl Acad Sci USA 2010;107:5184-9.

50. Teng YD, Lavik EB, Qu X, et al. Functional recovery following traumatic spinal cord injury mediated by a unique polymer scaffold seeded with neural stem cells. Proc Natl Acad Sci USA 2002;99:3024-9.

51. Jeyakumar M, Lee J-P, Sibson NR, et al. Neural stem cell transplantation benefits monogenic neurometabolic disorder during the symptomatic phase of disease. Stem Cells 2009;27:2362-70.

52. Ropper AE, Iraci N, Mercer TR, et al. Defining recovery neurobiology of injured spinal cord by synthetic matrix-assisted hMSC implantation. Proc Natl Acad Sci USA 2017;114:E820-9.

53. Riess P, Zhang C, Saatman KE, et al. Transplanted neural stem cells survive, differentiate, and improve neurologic motor function after experimental traumatic brain injury. Neurosurgery 2002;51:1043-52.
54. Bakshi A, Keck CA, Koshkin VS, et al. Neural progenitor cells engineered to secrete GDNF show enhanced survival, neuronal differentiation, and improve cognitive function following traumatic brain injury. Eur J Neurosci 2006;23:2119-34.

55. Cossetti C, Iraci N, Mercer TR, et al. Extracellular vesicles from neural stem cells transfer IFN- $\gamma$ via Ifngr1 to activate Stat1 signaling in target cells. Mol Cell. 2014;56:193-204.

56. Naphade S, Sharma J, Gaide Chevronnay HP, et al. Brief reports: lysosomal cross-correction by hematopoietic stem cell-derived macrophages via tunneling nanotubes. Stem Cells 2015;33:301-9.

57. Nagai M, Re DB, Nagata $T$, et al. Astrocytes expressing ALS-linked mutated SOD1 release factors selectively toxic to motor neurons. Nat Neurosci 2007;10:615-22.

58. Di Giorgio FP, Carrasco MA, Siao MC, et al. Non-cell autonomous effect of glia on motor neurons in an embryonic stem cell-based ALS model. Nat Neurosci 2007;10:608-14.

59. Windrem MS, Osipovitch M, Liu Z, et al. Human iPSC glial mouse chimeras reveal glial contributions to schizophrenia. Cell Stem Cell 2017;21:195-208.

60. Aboody KS, Brown A, Rainov NG, et al. Neural stem cells display extensive tropism for pathology in adult brain: evidence from intracranial tumors. Proc Natl Acad Sci USA 2000;97:12846-51.

61. Taylor RM, Lee J-P, Palacino JJ, et al. Intrinsic resistance of neural stem cells to toxic metabolites may make them well-suited for cell nonautonomous disorders: evidence from a mouse model of Krabbe leukodystrophy. J Neurochem 2006;97:1585-99.

62. Windrem MS, Windrem MS, Schanz SJ, et al. Neonatal chimerization with human glial progenitor cells can both remyelinate and rescue the otherwise lethally hypomyelinated shiverer mouse. Cell Stem Cell 2008;2: 553-65.

63. Wang S, Bates J, Li X, et al. Human iPSC-derived oligodendrocyte progenitors can myelinate and rescue a mouse model of congenital hypomyelination. Cell Stem Cell 2013;12:252-64.

64. Gupta N, Henry RG, Strober J, et al. Neural stem cell engraftment and myelination in the human brain. Sci Transl Med 2012;4:155ra137.

65. Park KI, Himes BT, Stieg PE, Tessler A, Fischer I, Snyder EY. Neural stem cells may be uniquely suited for combined gene therapy and cell replacement: evidence from engraftment of Neurotrophin-3-expressing stem cells in hypoxic-ischemic brain injury. Exp Neurol 2006;199:179-90.

66. Liu Y, Himes BT, Solowska J, et al. Intraspinal delivery of neurotrophin-3 (NT-3) using neural stem cells genetically modified by recombinant retrovirus. Exp Neurol 1999;158:9-26.

67. Rosario CM, Yandava BD, Kosaras B, Zurakowski D, Sidman RL, Snyder EY, Differentiation of engrafted multipotent neural progenitors towards replacement of missing granule neurons in meander tail cerebellum may help determine the locus of mutant gene action. Development 1997;124: 4213-24.

68. Fuentealba LC, Rompani SB, Parraguez JI, et al. Embryonic origin of postnatal neural stem cells. Cell 2015;161:1644-55.

69. Kriks S, Shim JW, Piao J, et al. Dopamine neurons derived from human ES cells efficiently engraft in animal models of Parkinson's disease. Nature 2011;480:547-1.

70. Snyder EY. The risk of putting something where it does not belong: mesenchymal stem cells produce masses in the brain. Exp Neurol 2011;230:75-7.

71. Lee RH, Pulin AA, Seo MJ, et al. Intravenous hMSCs improve myocardial infarction in mice because cells embolized in lung are activated to secrete the anti-inflammatory protein TSG-6. Cell Stem Cell 2009;5:54-63.

72. Seifert HA, Leonardo CC, Hall AA, et al. The spleen contributes to stroke induced neurodegeneration through interferon gamma signaling. Metab Brain Dis 2012;27:131-41. 